\title{
ACOPLAGEM DESIDROGENATIVA VIA CATÁLISE HETEROGÊNEA DE ETANOL E PROPANOL EM CATALISADOR DE COBRE SUPORTADO EM ZIRCÔNIA
}

\section{DEIDROGENATIVE COUPLING VIA HETEROGENEOUS CATALYSIS OF ETHANOL AND PROPANOL IN ZIRCONIA SUPPORTED COPPER CATALYSER}

\author{
A. F. C. ACERBI ${ }^{1}$, N. F. PERDIGÃO ${ }^{1}$, C. H. F. da CUNHA ${ }^{1}$ e A. G. SATO ${ }^{1}$ \\ ${ }^{1}$ Universidade Federal de Viçosa, Departamento de Química, Brasil \\ E-mail: ana.acerbi@hotmail.com
}

articleinfo

Article history:

Received 2017-07-05

Accepted 2017-09-13

Available online 2017-11-20

\author{
PALAVRAS-CHAVE: Catálise Heterogênea; Desidrogenação; Álcoois; Ésteres; Catalisador de Cobre; \\ $\mathrm{ZrO}_{2}$, Simulação Termodinâmica. \\ KEYWORDS: Heterogeneous Catalysis; Dehydrogenation; Alcohols; Esters; Copper Catalyst; ZrO2; \\ Thermodynamic Simulation.
}

RESUMO: Mudanças ambientais e climáticas observadas na atualidade têm aumentado a importância de processos de produção mais eficientes e sustentáveis. Neste contexto, uma alternativa interessante para a produção de ésteres é a reação de acoplagem desidrogenativa de álcoois. Este trabalho objetivou utilizar como substratos o etanol, propanol e diferentes misturas destes para realizar reações de acoplagem desidrogenativa em reator de leito fixo de escoamento descendente com catalisador de Cu/ZrO $\mathrm{Z}_{2}$. Para isso, foram realizados o preparo do catalisador e sua ativação tanto inicial quanto antes de cada reação. A análise dos produtos foi feita via CG-EM (Cromatografia Gasosa - Espectrometria de Massa), tendo-se encontrado diversos compostos, entre eles os ésteres acetato de etila, propionato de propila e etanoato de propila. Por fim foi feita uma análise termodinâmica das reações em Aspen Hysys para verificar as melhores condições de reação. As melhores condições foram maiores proporções de propanol nos reagentes e temperaturas entre $187,5^{\circ} \mathrm{C}$ e $200^{\circ} \mathrm{C}$.

\begin{abstract}
Current environmental and climatic changes have increased the importance of more efficient and sustainable production processes. In this context, an interesting alternative for esters production is the dehydrogenation coupling reaction of alcohols. This work aimed to use as substrates ethanol, propanol and different mixtures of these to carry out dehydrogenation coupling reactions in a downstream fixed bed reactor with $\mathrm{Cu} / \mathrm{ZrO} \mathrm{O}_{2}$ catalyst. For this, the preparation of the catalyst and its activation were carried out both before and after each reaction. The analysis of formed products was done with CG-EM, and several compounds were found, among them the ethyl acetate, propyl propionate and propyl ethanoate esters. Finally, a thermodynamic analysis was performed in Aspen Hysys to verify the best reaction conditions. The best conditions were higher proportions of propanol in the reagents and temperatures between $187,5^{\circ} \mathrm{C}$ and $200^{\circ} \mathrm{C}$.
\end{abstract}




\section{INTRODUÇÃO}

Durante o século XIX, os fenômenos catalíticos ganharam destaque, sendo que em 1834 a primeira patente de catalisadores foi publicada, empregando platina na oxidação de enxofre e de dióxido de enxofre (LOHSE, 1945). A catálise revolucionou a indústria, sendo hoje responsável por aproximadamente $85 \%$ de todos os processos químicos e petroquímicos (CIOLA, 1981).

Em especial, a catálise heterogênea possui diversas vantagens, como eliminação de problemas de corrosão, facilidade de separação de produtos e catalisador, e no tratamento dos resíduos. Pode também possuir desvantagens como limitações de transferência de massa e dificuldade de controle de temperaturas em reações exotérmicas. No entanto, as vantagens parecem superar as desvantagens, já que os catalisadores heterogêneos são os mais utilizados na indústria. (DELANNAY, 1984).

No contexto de catálise heterogênea, neste trabalho deu-se destaque às reações heterogêneas do tipo acoplagem desidrogenativa. É um tipo de reação que pode substituir métodos tradicionais de produção, trazendo benefícios ambientais e econômicos, principalmente quando se observa a necessidade de modificar métodos tradicionais de produção de ésteres ou outros compostos a partir de álcoois.

A acoplagem desidrogenativa tem o potencial de substituir atuais processos de esterificação e transesterificação, que normalmente utilizam substâncias danosas ao meio ambiente, como ácidos. Além disso, pode facilitar a produção industrial, já que permite a formação mais direta de produto, evitando a necessidade de diversas etapas, e produz hidrogênio, que pode ser utilizado como combustível.

Diferentes tipos de catalisadores têm sido usados para a reação de desidrogenação como zeólitas, peneiras moleculares e zinco. No entanto, catalisadores a base de cobre têm apresentado grande seletividade para reações de hidrogenação e desidrogenação de álcoois (RAO, 1997). Além disso, o cobre tem um preço relativamente baixo, sendo mais barato, por exemplo, que o níquel e que a platina (London Metal Exchange, Kitco Metals Inc., 2017).

As características catalíticas do cobre podem ser influenciadas pelo suporte utilizado na reação e pela dispersão do componente ativo. No caso do suporte de zircônia, esta tem sido descrita como elemento preventivo na sinterização de cristais de cobre, possuidora de alta estabilidade térmica e alta estabilidade sob condições de redução. Além disso, a $\mathrm{ZrO}_{2}$ atua como suporte bifuncional, apresentando sítios ácidos e básicos que a tornam útil em diversas aplicações (SHIMOKAWABE; ASAKAWA; TAKEZAWA, 1990). Para a conversão do etanol a acetato de etila, por exemplo, melhores resultados são obtidos para catalisadores de cobre suportados por óxido de zircônio tetragonal (SATO, 2012).

Tendo em vista o exposto, considerou-se uma alternativa interessante a utilização de cobre como catalisador em um suporte de zircônia para a realização de reações de acoplagem desidrogenativa por catálise heterogênea. Um dos objetivos específicos desse trabalho foi a síntese do catalisador sólido a base de cobre suportado por zircônia. A desidrogenação do etanol para produção de acetato de etila utilizando cobre como catalisador já havia sido descrita por Dario de Carvalho (2010, p. 32) como uma nova tecnologia com potencial 
relevante para ser aplicada em regiões brasileiras com disponibilidade de etanol a custo competitivo. André Gustavo Sato (2012, pg. 1) concluiu que o cobre suportado na $\mathrm{ZrO}_{2}$ é um catalisador extremamente ativo e seletivo para transformar o etanol diretamente em acetato de etila. No entanto, a acoplagem desidrogenativa catalítica com propanol e a mistura etanol/propanol ainda não foi bem estabelecida (YAMAGUCHI, 1994. TANABE, YAMAGUCHI, 1994). Dessa forma, o objetivo principal deste trabalho foi contribuir para o conhecimento científico na área de reações heterogêneas do tipo acoplagem desidrogenativa com etanol e propanol catalisadas por $\mathrm{Cu} / \mathrm{ZrO}_{2}$.

Para análise qualitativa destes produtos - um dos objetivos do presente trabalho, o método CG-EM (Cromatografia Gasosa - Espectrometria de Massa) pode ser utilizado com alta precisão, funcionando por meio da combinação da cromatografia gasosa e da espectrometria de massas (ARDREY, 2003, apud CHIARADIA; COLLINS; JARDIM, 2008). Na cromatografia gasosa (CG) ocorre a partição dos componentes entre uma fase móvel gasosa e uma fase estacionária (líquida ou sólida), sendo ideal para componentes voláteis e termicamente estáveis, como é o caso dos reagentes deste trabalho. Na espectrometria de massas (EM), moléculas em uma amostra são convertidas em íons em fase gasosa, que são então separados no espectrômetro de massas de acordo com sua razão massa/carga. O instrumento é calibrado com padrões cujas massas são conhecidas com alta precisão (WILSON, WALKER, 2010).

Uma das etapas fundamentais desse estudo é a análise termodinâmica das reações, permitindo comparar as condições ideais de reação com as condições reais de formação dos produtos desejados na presença de catalisador. Para isso, pode-se utilizar o método da minimização da energia de Gibbs, que é baseado em um princípio termodinâmico rigoroso: em um sistema fechado com temperatura e pressão constantes, a energia livre de Gibbs atinge um mínimo. Assim, a composição de equilíbrio é independente do mecanismo de reação, mas é determinada pela composição da alimentação do reator, sua pressão e temperatura (DEREVICH, 2006).

Uma ferramenta para cálculo das condições ideais de reação pelo método de minimização da energia de Gibbs é o programa Aspen Hysys. Este utiliza o método de contribuição de grupos de Joback para calcular uma série de propriedades termoquímicas como função de um grupo de parâmetros (JOBACK, 1987). Posteriormente, com os dados disponíveis, realizam-se cálculos de minimização da energia de Gibbs, fornecendo composições de produtos em determinadas temperaturas e pressões quando no equilíbrio.

\section{MATERIAIS E MÉTODOS}

\subsection{Materiais e Equipamentos}

Materiais: Os materiais utilizados foram ar sintético $\left(\mathrm{O}_{2} / \mathrm{N}_{2}\right.$, Inerte, $\left.99,999 \%\right)$, nitrato de cobre trihidratado $\left(\mathrm{Cu}\left(\mathrm{NO}_{3}\right)_{2} \cdot \mathrm{H}_{2} \mathrm{O}, 98 \%\right.$, Marca Dinâmica), zircônia $\left(\mathrm{ZrO}_{2}\right.$, área de superfície $55 \mathrm{~m}^{2} / \mathrm{g}$, Pureza $<0,2 \% \mathrm{SiO}_{2}$, Marca NorPro) e metanol $\left(\mathrm{CH}_{3} \mathrm{OH}, 99,8 \%\right)$ para síntese do catalisador; gás hidrogênio $\left(\mathrm{H}_{2}\right.$, Inflamável, $\left.99,999 \%\right)$ para ativação do catalisador; gás hélio (He, Inflamável, 99,999\%) para arraste dos reagentes vaporizados até o interior do reator; além dos reagentes etanol $\left(\mathrm{CH}_{3} \mathrm{CH}_{2} \mathrm{OH}, 99,8 \%\right.$, Marca Vetec) e propanol $\left(\mathrm{CH}_{3} \mathrm{CH}_{2} \mathrm{CH}_{2} \mathrm{OH}, 99,7 \%\right.$, Marca Sigma-Aldrich). 
Equipamentos: Os equipamentos utilizados foram balança analítica Shimadzu, modelo AUY220 (Erro 0,001g), para pesagem do nitrato de cobre trihidratado e zircônia durante a etapa de síntese do catalisador; bomba seringa Nikkiso, modelo PSK-01, classe II, tipo BF, para injeção dos reagentes no reator/saturador; Cromatógrafo Gasoso para espectrometria de massas Shimadzu, modelo GC-2010 Plus, para análise qualitativa dos produtos das reações; dessecador Pyrex, e estufa Fanem, utilizados durante a síntese do catalisador, e o reator/Saturador em U com leito fixo (Borossilicat, diâmetro $5 \mathrm{~mm}$ ), no interior do qual ocorreram as reações de acoplagem desidrogenativa.

\subsection{Metodologia}

Metodologia de síntese do catalisador: Preparou-se $1 \mathrm{~g}$ de catalisador em pó, composto por $10 \%$ de cobre e $90 \%$ de zircônia. Como fonte de cobre, utilizou-se nitrato de cobre trihidratado. A equação 1 mostra o cálculo de ajuste da composição do catalisador, resultando em aproximadamente $0,381 \mathrm{~g}$ de nitrato de cobre trihidratado.

$$
m_{\text {tøórica, Cu(NO } \left.\mathrm{n}_{2}\right)_{2}, 3 \mathrm{H}_{2} \mathrm{O}}=\frac{241,6 \frac{\mathrm{gCu}\left(\mathrm{NO}_{3}\right)_{2} \cdot 3 \mathrm{H}_{2} \mathrm{O}}{\mathrm{mol} \mathrm{Cu}\left(\mathrm{NO}_{3}\right)_{2} \cdot 3 \mathrm{H}_{2} \mathrm{O}} * 0,1 \mathrm{gCu}}{63,5 \frac{\mathrm{gCu}}{\mathrm{mol} \mathrm{Cu}\left(\mathrm{NO}_{3}\right)_{2} \cdot 3 \mathrm{H}_{2} \mathrm{O}}}
$$

A massa teórica de nitrato de cobre trihidratado necessária foi corrigida de acordo com a pureza de $98 \%$ do composto, calculando-se então a massa real demandada através da equação 2 .

$$
m_{\text {real }, \mathrm{Cu}\left(\mathrm{NO}_{\mathrm{s}}\right)_{2} \cdot 3 \mathrm{H}_{2} \mathrm{O}}=\frac{0,381 \mathrm{~g}}{0,98}=0,388 \mathrm{gCu}\left(\mathrm{NO}_{3}\right)_{2} \cdot 3 \mathrm{H}_{2} \mathrm{O}
$$

Foram então pesados $0,4012 \mathrm{~g}$ de nitrato de cobre trihidratado em balança analítica, um valor próximo ao estimado em (2), que foi diluído em metanol, para facilitar o gotejamento do composto em $0,9 \mathrm{~g}$ de zircônia. $\mathrm{O}$ metanol foi eliminado nas etapas posteriores de preparo do catalisador, como gás, a $40^{\circ} \mathrm{C}$. O sistema foi encaminhado à estufa por 2 horas, para desidratação, passando depois para o dessecador, onde permaneceu até ser inserido no interior do reator. A calcinação do catalisador no reator ocorreu durante 2 horas, com passagem de ar sintético, para decomposição do nitrato.

Metodologia de ativação do catalisador: Adicionou-se o catalisador ao tubo destinado a ele no Reator/Saturador. Durante a ativação do catalisador, a temperatura do forno foi ajustada para $250^{\circ} \mathrm{C}$, a uma taxa de aquecimento de $25^{\circ} \mathrm{C} / \mathrm{min}$. No instante em que o visor do controlador digital de temperatura do forno indicou $220^{\circ} \mathrm{C}$, a taxa de aquecimento foi reduzida para $5^{\circ} \mathrm{C} / \mathrm{min}$. Ajustou-se o fluxo volumétrico de gás hidrogênio pelo reator para 50 $\mathrm{mL} / \mathrm{min}$. Com as condições de operação ajustadas, a ativação do catalisador ocorreu durante um intervalo de 2 horas. 
Metodologia de realização das reações: Antes de cada reação, foi necessária nova ativação de todo o catalisador produzido, durante 30 minutos, com a passagem de gás hidrogênio pelo reator numa vazão de $50 \mathrm{ml} / \mathrm{min}$. Os reagentes foram inseridos no vaporizador, com auxílio de uma bomba seringa, à uma vazão de alimentação de $2 \mathrm{ml} / \mathrm{h}$, simultaneamente a inserção de gás hélio, numa vazão de $10 \mathrm{ml} / \mathrm{min}$. O tempo de residência dos reagentes foi fixado de acordo com o volume de produto que se desejou produzir.

Metodologia de análise dos produtos: Os produtos da reação do etanol, propanol, etanol-propanol na mistura 1:1 foram analisados qualitativamente através do método CG-EM. Com os resultados gerados pelo equipamento, produziu-se um espectro de massa no software Origin, mostrando a intensidade relativa de cada íon que aparecia como picos com razão massa/carga definida.

Ao final, foi realizada simulação das reações etanol/propanol em programa Aspen Hysys a partir do método de minimização da energia de Gibbs. Inseriram-se no programa a concentração dos reagentes etanol e propanol nas proporções estequiométricas 1:1, 1:3 e 3:1, a fim de se analisar tanto a reação experimental quanto o possível efeito da influência do excesso de propanol e etanol. Para os produtos de cada uma destas reações, foram inseridos os dados de produtos encontrados por análise em CG-EM da reação etanol/propanol 1:1, permitindo encontrar a concentração final de equilíbrio ideal dos produtos em diferentes temperaturas.

\section{RESULTADOS E DISCUSSÃO}

A reação de acoplagem desidrogenativa do etanol apresentou-se bastante seletiva, com a formação do intermediário acetaldeído e o produto principal acetato de etila, como pode ser verificado na figura 1 . Os resultados da figura 1 foram gerados pelo equipamento CG-EM e reportados pelo software Origin. Os picos menores representam compostos detectados em baixa quantidade no produto, supostamente impurezas, que não foram, por isso, englobadas no presente estudo.

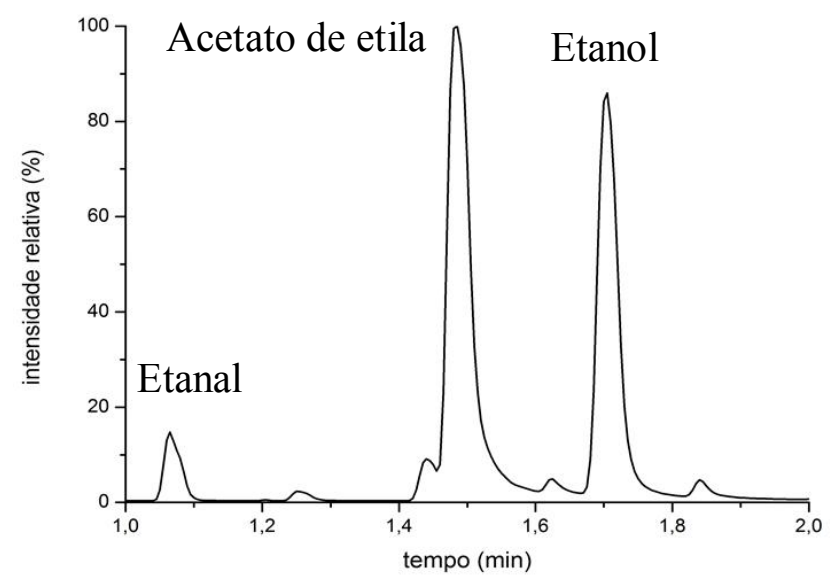

Figura 1 - Intensidade relativa versus tempo para análise do produto da desidrogenação do etanol. 
O terceiro pico (tempo de retenção 1,72 ) representa o reagente que não foi convertido, saindo junto dos produtos. De acordo com Inui e colaboradores (INUI; KURABAYASHI; SATO, 2002), que estudaram a rota de desidrogenação de formação de acetato de etila a partir do etanol, o etanol é inicialmente desidrogenado, com a formação de etanal. Depois, o etanal reage com uma espécie de etóxi para formar hemiacetal. Este sofre nova desidrogenação resultando no acetato de etila.

A reação de acoplagem desidrogenativa do propanol também se mostrou bastante seletiva, com a formação de um intermediário e um produto principal, como pode ser visto na figura 2, de acordo com os resultados gerados pelo equipamento CG-EM.

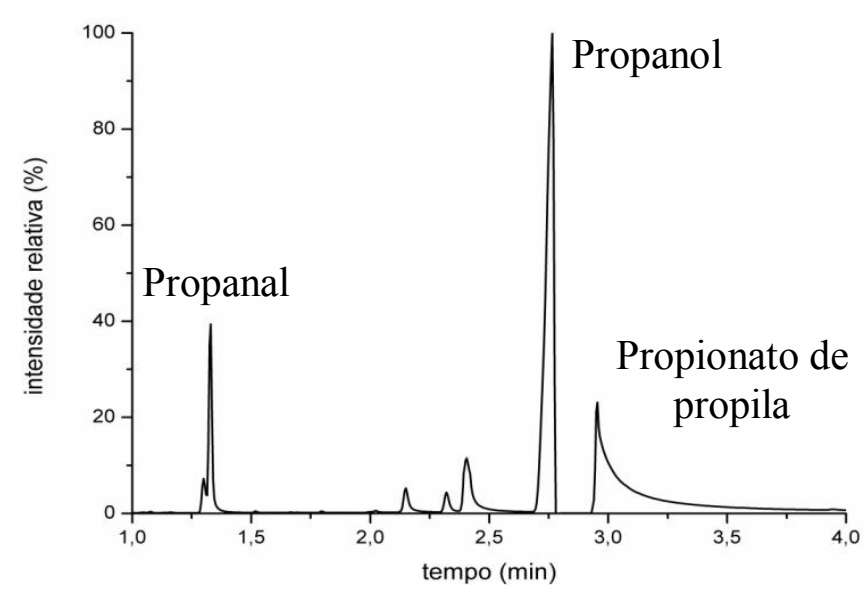

Figura 2 - Intensidade relativa versus tempo para análise do produto da desidrogenação do propanol.

O segundo pico considerado na figura 2 representa o reagente que não foi convertido. A partir do estudo feito por Inui e colaboradores (INUI; KURABAYASHI; SATO, 2002) sobre a rota de desidrogenação de formação de acetato de etila a partir do etanol, presume-se que o mecanismo de reação seja semelhante para a desidrogenação do propanol. O propanol é inicialmente desidrogenado, com a formação de propanal. Depois, o propanal reage com uma espécie de propóxi para formar hemiacetal. Este sofre nova desidrogenação resultando no propionato de propila.

Após consideração das figuras 1 e 2, percebe-se a importância de um estudo termodinâmico sobre a reação de acoplagem desidrogenativa do etanol e propanol, de forma a se conhecer os valores ótimos de temperatura no interior do reator durante a reação que levam a máxima conversão dos aldeídos intermediários nos ésteres de interesse. Essa investigação foi previamente feita por Cunha (CUNHA, 2016), servindo como estudo modelo para análise termodinâmica dos produtos da reação entre etanol e propanol.

$\mathrm{Na}$ reação de etanol com propanol 1:1 ocorreu a formação de diversos produtos, identificados em CG-EM e enumerados de 1 até 15 na figura 3. A correspondência destes números é especificada na tabela 1 . 


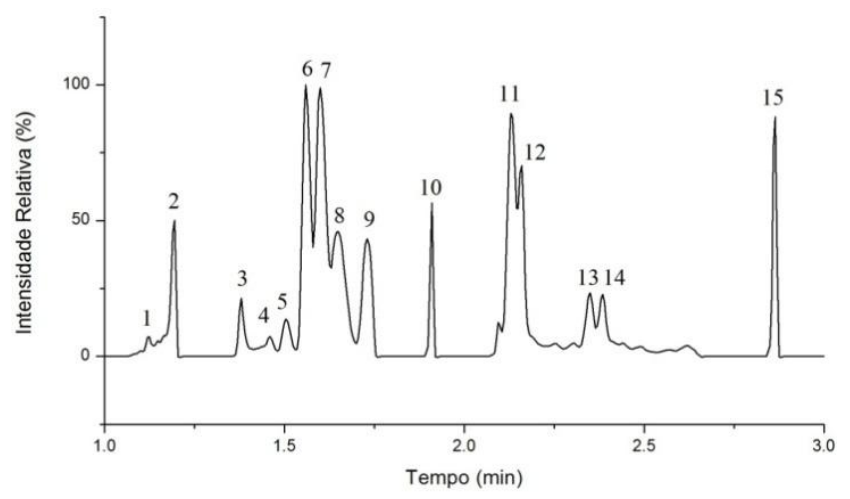

Figura 3 - Intensidade relativa versus tempo para análise do produto da desidrogenação da mistura etanol/propanol 1:1.

Tabela 1 - Resultados de análise dos picos pela biblioteca do CG-EM.

\begin{tabular}{|c|c|c|}
\hline Número & Compostos mais prováveis & Probabilidade (\%) \\
\hline \multirow[t]{2}{*}{1} & 2-penteno & 95 \\
\hline & 2-metil-buteno & 95 \\
\hline \multirow[t]{2}{*}{2} & Formiato de vinila & 92 \\
\hline & Etóxi eteno & 91 \\
\hline \multirow[t]{2}{*}{3} & 2-metil-heptanal & 87 \\
\hline & 1-metiletóxi-1-propeno & 87 \\
\hline 4 & 2-octeno & 90 \\
\hline \multirow[t]{5}{*}{5} & 7-octen-4-ol & 87 \\
\hline & Trans-1-etóxi-1-buteno & 87 \\
\hline & 3-etóxi-2-metil-1-propeno & 87 \\
\hline & 2-hexen-1-ol & 87 \\
\hline & 3,3-dimetil-2-butanona & 87 \\
\hline 6 & Butanal & 97 \\
\hline 7 & Acetato de etila & 95 \\
\hline 8 & 1,1-dietóxi-etano & 91 \\
\hline 9 & 2-metil-butanol & 97 \\
\hline 10 & Etanol & 91 \\
\hline 11 & $\begin{array}{l}\text { Propionato de etila ou } \\
\text { Acetato de n-propila }\end{array}$ & 92 \\
\hline \multirow[t]{2}{*}{12} & Pentanal & 92 \\
\hline & 3-metil-butanal & 91 \\
\hline 13 & 2-etil-butanal & 96 \\
\hline \multirow[t]{2}{*}{14} & 4-metil-pentanal & 96 \\
\hline & 2-metil-pentanal & 95 \\
\hline 15 & Propanol & 95 \\
\hline
\end{tabular}


Sabe-se que o CG-EM mostra como resultado de análise a probabilidade de determinado composto ser o representativo de um pico. Sendo assim, alguns produtos que mostraram baixa probabilidade, ou alta probabilidade mas que competiam com outros tipos de compostos para representarem o pico, foram descartados da análise, merecendo futuramente um estudo sobre os possíveis mecanismos de reação que os geraram.

Os compostos desconsiderados foram os de número $1,3,4,5,8,9,13$ e 14 da figura 3. Novo resultado apenas com os produtos mais prováveis é mostrado na figura 4.

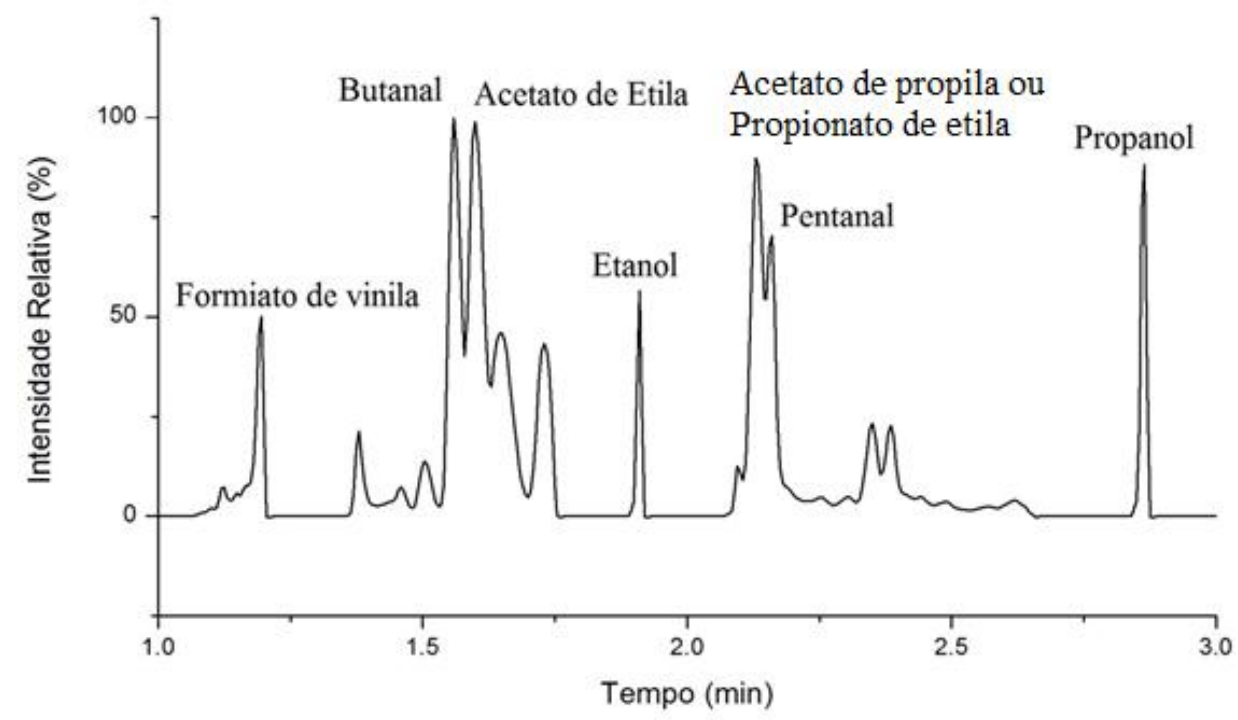

Figura 4 - Intensidade relativa versus tempo para análise apenas dos produtos mais prováveis da desidrogenação da mistura etanol/propanol 1:1.

A formação do acetato de etila a partir de etanol era esperada, de acordo com o estudo de Inui e colaboradores (INUI; KURABAYASHI; SATO, 2002), discutido anteriormente. Os produtos propionato de etila e acetato de propila são compostos previsíveis para a reação de acoplagem desidrogenativa de etanol com propanol. Pode-se supor que o acetaldeído ou o etóxi, que, como dito antes, provavelmente são formados a partir do etanol como intermediários da reação, reajam com propanal ou propóxi formados a partir do propanol também como intermediários. Tanto a reação de um propóxi com acetaldeído ou etóxi com propanal pode levar à formação de um hemiacetal que, após desidrogenação, forma propionato de etila e acetato de propila.

Não tendo encontrado na literatura mecanismo compatível para formação de formiato de vinila, pentanal e butanal a partir da mistura etanol-propanol, preferiu-se aguardar futura análise mais aprofundada que possa fornecer uma explicação razoável para a rota de formação destes compostos. Etanol e propanol que constam no espectro representam os reagentes não convertidos, sendo necessária uma análise termodinâmica para determinação das condições ideais de maximização da conversão de reagentes.

Para analisar a temperatura ideal para a produção de ésteres de interesse, foi realizada 
uma análise no programa Aspen Hysys, onde se simulou a reação de propanol e etanol em proporção 1:1, 1:3 e 3:1 em reator de Gibbs com a formação dos intermediários acetaldeído e propionaldeído, assim como os produtos acetato de etila, propionato de propila e propionato de etila. Naturalmente, esta análise não representa a realidade, já que como visto, houve a formação de diversos outros subprodutos decorrentes da acoplagem desidrogenativa experimental de misturas de etanol e propanol. Ainda, esta análise é essencialmente termodinâmica, sendo fundamental para análise completa da reação uma avaliação cinética unida à termodinâmica, procurando obter a melhor sinergia entre estas duas. No entanto, serve como ponto de partida para futuros experimentos com esta reação.

Como o acetato de etila é formado através da reação com etanol puro e propionato de propila é formado a partir da reação com propanol puro, os produtos mais interessantes para a reação de etanol e propanol juntos seriam o acetato de propila ou propionato de etila. Assim, procurou-se a proporção e temperatura que pudessem favorecer a formação destes dois últimos. Os resultados da simulação de etanol e propanol na proporção 1:1 são mostrados na figura 5.

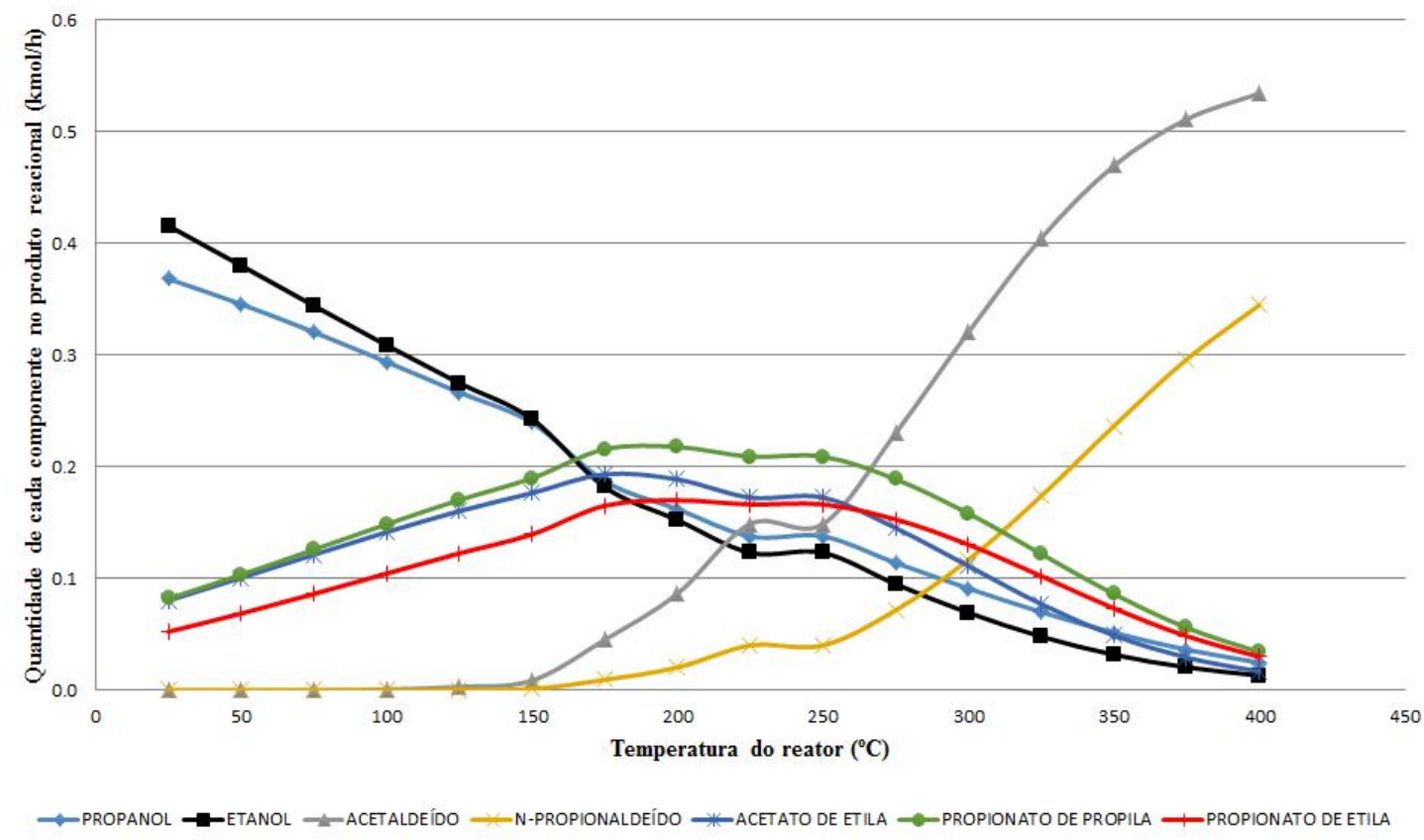

Figure 5 - Ensaio termodinâmico para determinação de temperaturas ótimas da reação etanol-propanol 1:1.

$\mathrm{Na}$ figura 5, observa-se que o acetaldeído e o n-propionaldeído apresentaram maior concentração que os demais componentes a partir da temperatura de $325^{\circ} \mathrm{C}$. Portanto, nesta temperatura os intermediários são formados em maior quantidade em relação aos produtos finais, presumindo-se que a reação, sob essa condição de temperatura, não prossegue como desejado. A temperatura ótima para formação dos ésteres foi de aproximadamente $187,5^{\circ} \mathrm{C}$. Vê-se que nesta temperatura produz-se maior quantidade de propionato de etila, que é um dos principais produtos que se queria obter com a reação. 
Os resultados da simulação de etanol e propanol na proporção 3:1 são mostrados na figura 6 .

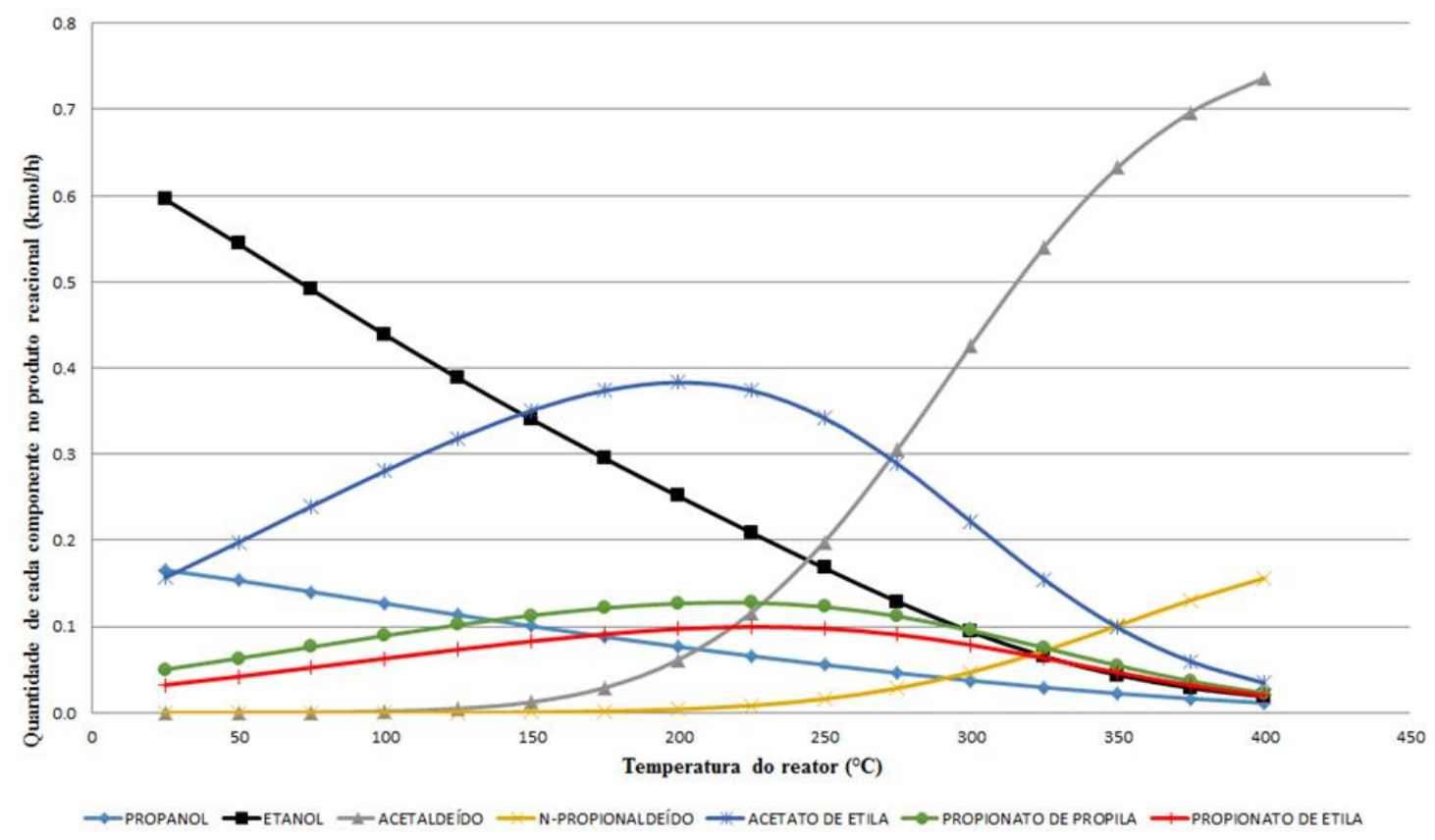

Figure 6 - Ensaio termodinâmico para determinação de temperaturas ótimas da reação etanol-propanol 3:1.

Na figura 6 observa-se que ocorreu maior formação de acetaldeído e n-propionaldeído em relação aos outros produtos, na temperatura de $350^{\circ} \mathrm{C}$, sendo que este primeiro está sendo muito mais favorecido que o segundo. A partir de altas temperaturas, portanto, os intermediários são formados predominantemente, presumindo-se que esta faixa de temperatura não é ideal para a formação de produtos de maior valor agregado, os ésteres. A faixa de temperatura ótima para formação dos ésteres foi de aproximadamente $200^{\circ} \mathrm{C}-225^{\circ} \mathrm{C}$. A formação de acetato de etila se sobressaiu à dos demais ésteres sob todas as temperaturas de ensaio, o que não é desejado já que este produto já é formado na reação de etanol individualmente.

Os resultados da simulação de etanol e propanol na proporção 1:3 são mostrados na figura 7 . 


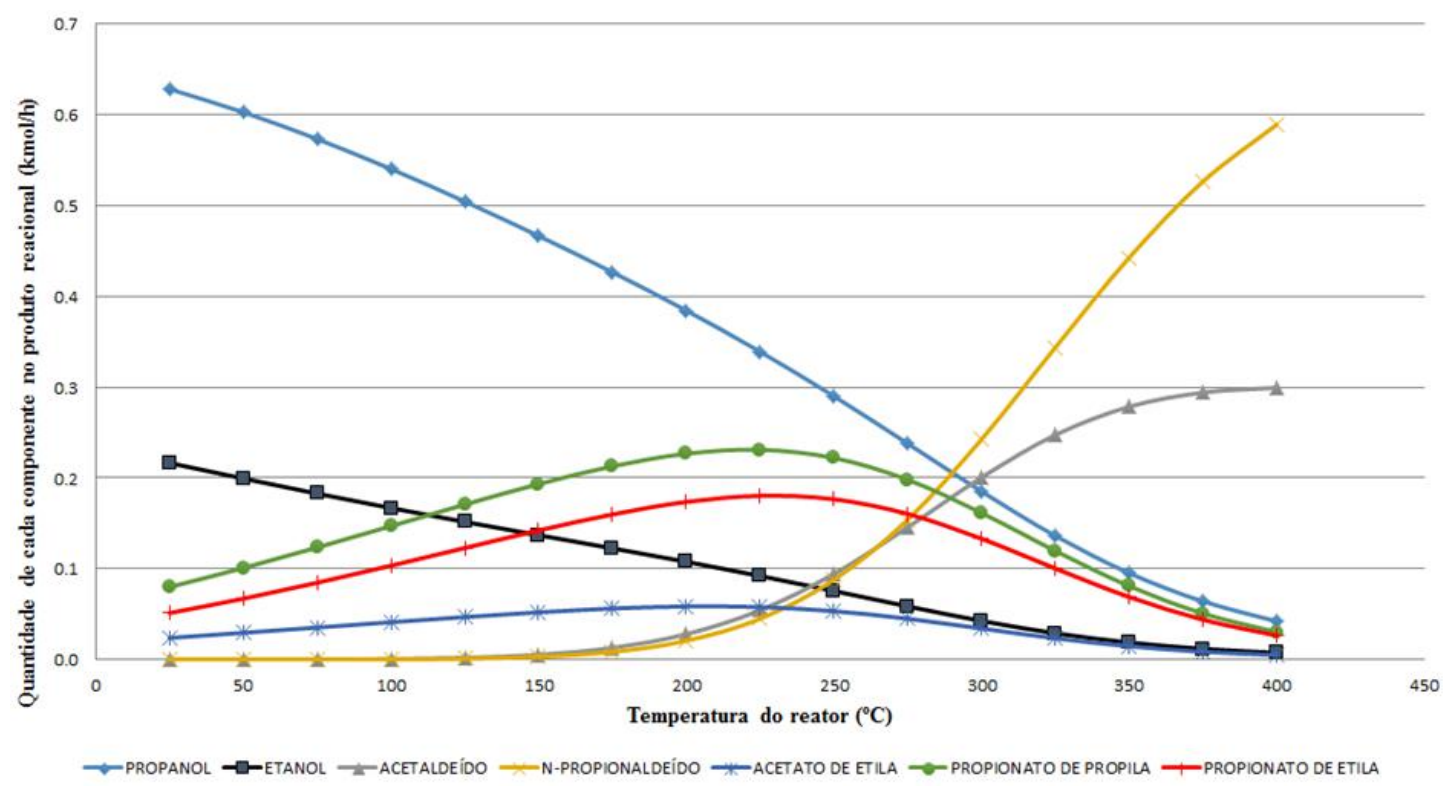

Figura 7 - Ensaio termodinâmico para determinação de temperaturas ótimas da reação etanol-propanol 1:3.

$\mathrm{Na}$ figura 7, observa-se que os aldeídos acetaldeído e n-propionaldeído se sobressaem em termos de concentração em relação aos demais produtos a partir da temperatura de $300^{\circ} \mathrm{C}$. Assim, não sugere-se realizar a reação nesta temperatura, já que os intermediários estão sendo formados em maior quantidade que os ésteres, que são os produtos de interesse. A temperatura ótima para formação dos ésteres foi de cerca de $220^{\circ} \mathrm{C}$. A formação de propionato de etila neste ensaio se sobressaiu em relação a quantidade formada deste éster em todas as temperaturas dos demais ensaios, sendo então a proporção 1:3 a mais adequada para formação de um produto que não é formado pelas reações individuais de etanol e propanol. Supõe-se que maiores proporções de propanol aumentam a seletividade de formação de propionato de etila, sendo interessante realizar mais estudos com esta condição.

Em todas as análises termodinâmicas, foi possível observar que o aumento da formação de aldeídos com a temperatura levou à diminuição da formação de ésteres, podendo-se supor que provavelmente, dependendo da temperatura, a formação de aldeídos seja favorecida e sua formação atrapalha a formação de ésteres. Para a comprovação disso, seriam necessárias análises de reações etanol/acetaldeído, propanol/propionaldeído e assim por diante.

É importante observar na análise termodinâmica que em temperaturas menores (até $150^{\circ} \mathrm{C}$ ) não há formação de aldeídos, o que seria favorável no caso do interesse ser apenas voltado à produção de ésteres, pois nesta faixa de temperatura não ocorreria a formação de subprodutos.

Em estudos anteriores em que se utilizou o catalisador de cobre suportado em zircônia em condições reacionais parecidas com as do presente estudo (SATO, 2012), verificou-se que o modelo de reação do etanol formando acetato de etila seria do tipo Langmuir-Hinshelwood (Figura 17). Sendo assim, como o propanol também é um álcool de baixo peso molecular, supõe-se que o modelo de Langmuir-Hinshelwood poderia se ajustar às reações de 
acoplagem desidrogenativa de propanol e misturas de etanol/propanol, aspecto que deverá ser investigado por futuros estudos.

\section{CONCLUSÕES}

Ao final do trabalho todos os objetivos desejados foram alcançados. Contribuiu-se com o conhecimento cientifico na área de catálise heterogênea ao mostrar diversas características novas da reação de acoplagem desidrogenativa de etanol com propanol em catalisador de $\mathrm{Cu} / \mathrm{ZrO}_{2}$. Os produtos prováveis deste tipo de reação com o reagente etanol são: acetaldeído e acetato de etila. Os produtos prováveis desta reação com o reagente propanol são: propanoato de propila e propionaldeído. Na reação com ambos os reagentes, os produtos prováveis são: butanal, acetaldeído, propionaldeído, acetato de etila, propionato de propila e etanoato de propila/propionato de etila. Foram propostos mecanismos de reação para a formação dos ésteres baseados em intermediários, suposição que poderá ser comprovada em estudos mais avançados. Foi encontrada proporção adequada de substrato para a formação do etanoato de propila/propionato de etila, que seria 1:3 etanol/propanol, sugerindo-se investigar experimentalmente os resultados do uso de maiores proporções de propanol. Análise termodinâmica demonstrou uma melhor formação de ésteres na faixa de temperatura entre $187,5^{\circ} \mathrm{C}$ e $200^{\circ} \mathrm{C}$.

\section{REFERÊNCIAS}

ARDREY, R. E. Liquid chromatography-mass spectrometry: an introduction. John Wiley \& Sons, 2003.

CARVALHO, D. Produção de acetato de etila em biorrefinaria: uma análise de viabilidade. Diss. 2010.

CHIARADIA, M. C.; COLLINS, C. H.; JARDIM, I. C. O estado da arte da cromatografia associada à espectrometria de massas acoplada à espectrometria de massas na análise de compostos tóxicos em alimentos. Química nova, 2008.

CIOLA, R. Fundamentos da catálise. São Paulo: Universidade de São Paulo, 1981. p. 377.

CUNHA, C. H. F.; Avaliação da conversão seletiva de terpenos em terpenóides funcionalizados via catálise heterogênea em reator de leito fixo em regime de fluxo contínuo. Trabalho de Conclusão de Curso - Departamento de Química, Universidade Federal de Viçosa, Viçosa, 2016.

DELANNAY, F. Characterization of heterogeneous catalysts. New York: Marcel Dekker, 1984. p. 404.

DEREVICH, I. V. et. al. Calculation of the Reforming of Oil Gas by Minimizing the Gibbs Free.

INUI, K.; KURABAYASHI, T.; SATO, S. Direct synthesis of ethyl acetate from ethanol over Cu-Zn-Zr-Al-O catalyst. Applied Catalysis A: General, v. 237, p. 53-61, 2002.

JOBACK K. G., REID R. C. Estimation of Pure-Component Properties from GroupContributions. Chem. Eng. Commun,1987.

LOHSE, H. W. Catalytic chemistry. New York: Chemical Publishing, 1945. p. 175.

London Metal Exchange. 2017. Disponível em: < http://www.lme.com/ >.

RAO, R. et al. Properties of Copper Chromite Catalysts in Hydrogenation Reactions. Journal of Catalysis, v. 171, p. 406-419, out. 1997. 
SATO, A. G. Propriedades eletrônicas e estruturais do $\mathrm{Cu} / \mathrm{ZrO2}$ aplicadas à reação do etanol. Tese (Doutorado em Engenharia Química) - Centro de Ciências Exatas e de Tecnologia, Universidade Federal de São Carlos, São Carlos, 2012.

SHIMOKAWABE, M.; ASAKAWA, H.; TAKEZAWA, N. Characterization of copper/zirconia catalysts prepared by an impregnation method. Applied Catalysis, v. 59, p. $45-58,1990$.

WILSON, K.; WALKER, J. Principles and techniques of biochemistry and molecular biology. Cambridge University Press, 2010.

YAMAGUCHI, T. Application of $\mathrm{ZrO2}$ as a catalyst and catalyst support. Catalysis Today, v. 20, p. 199-218, 1994. 